\title{
Emerging eHealth Directions in the Philippines
}

\author{
P. G. Fernandez-Marcelo, B. L. Ho, J. F. Faustorilla Jr, A. L. Evangelista, M. Pedrena, \\ A. Marcelo \\ University of the Philippines Manila - National Telehealth Center
}

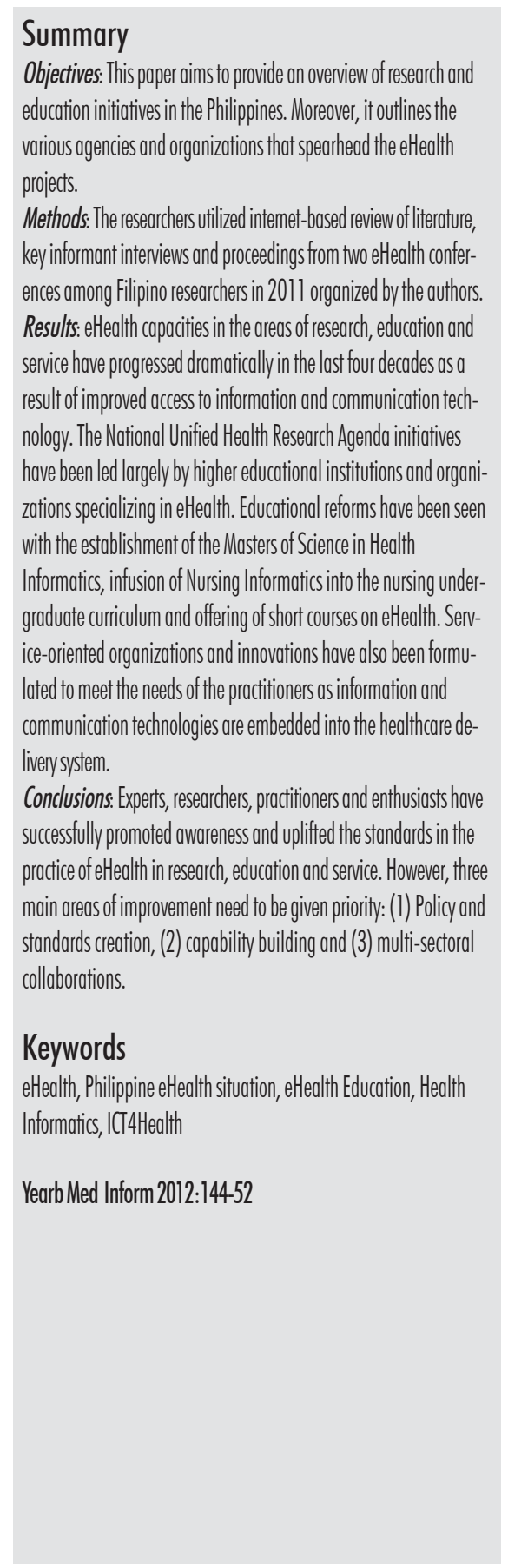

\section{Introduction}

Recent developments in manufacturing have made information and communications technology (ICT) more affordable and accessible. As such, they have become fundamental tools in solving many of the problems in low-to-medium income countries, including health. eHealth is "the use of ICT for health, which includes caring for patient, conducting health research, educating the health workforce, tracking diseases and monitoring population health" (WHO, 2012). eHealth is often interchangeably used with medical, health or biomedical informatics.

The Philippines is an archipelago of 7,107 islands in Southeast Asia. The 2010 census estimated a total of 94 million Filipinos, with youths below 21 years old occupying half of the population and even as the elderly population has grown to $4.19 \%$. Considered a low to middle-income country, the Philippines has $63 \%$ of its population living in urban centers.

In recent years, ICT use in daily life has escalated to a level where about 80 million Filipinos have mobile phones and almost all rural villages have cellular signals. Mobile phone penetration is reported to be significant, with 63 of the 80 provinces having a fibre-based infrastructure of at least one operator, covering at least the main urban area and typically a major transmission route passing through the provinces. The Philippines, having one of the highest usage rates of short messaging systems (SMS), has been dubbed the "texting capital of the world" (ITU, 2011). With mobile Internet increasingly becoming more af- fordable, it is expected that usage in the country will soar as commensurately.

As early as 1994, Jayasuriya (1995) had already cited challenges with the country's health information systems. The author describes "the existence of major gaps in information, the inappropriateness of the available information for the needs and most evidently that information is not utilized for management at most levels." At that point, capability building programs for health information systems had just begun to be developed like the Field Epidemiology Training Program of the Department of Health (National Epidemiology Center, n.d.).

The first documented eLearning and telehealth activity in the country was in 1985 , when the country became part of the SatelLife-Healthnet project which linked medical centers in the United States and the Philippines. The system provided e-mail communications and other services via the LEO Healthsat satellites. In 1991, the Makati Medical Center and initiated a series of videoconferences with Stanford University Hospital.

\section{Starting Points: National Studies on ellealth Capacities}

Rudiments of eHealth in the Philippines can be gleaned in the 1960s when clinical residency training programs were formalized and resident physicians began using the telephone incrementally to consult more senior clinicians on the management of hospitalized patients. Then, for almost two decades, beepers became ubiquitous to alert and inform 
clinicians on patient status. As cellular phones and short messaging systems or SMS became more affordable at the turn of the century, it replaced landlines and beepers a major mode of communications in medical care.

In 2007, the Philippine Health Information Network, led by the Department of Health, with the support of the World Health Organization and the Health Metrics Network embarked on an evaluation of the Philippine Health Information System using the Health Metrics Network. Key finding are as follows: (1) HIS institutions, human resources and financing are inadequate (2) IT and database support to HIS staff is adequate only at national level, but not at the subnational level. Telephone access and internet connection are still problematic. (3) Electronic processing of the field health survey information system (FHSIS) is leadership-dependent, and in-depth analysis is lacking. (4) Lack of funding and non-priority have been cited as reasons for not providing capacitybuilding activities for HIS.

In 2009, the WHO conducted the second global survey on eHealth (WHO, 2011, pp. 182-183); this is based on self-reporting by a selected group of eHealth expert informants for each 114 participating countries, including that of the Philippines. The survey revealed that there exists ICT training both formal and non-degree courses for students and health professionals alike. Funding for these skills training and scholarships come from the government, private sector, donor organization and public-private partnerships. eLearning, while used in the health sciences, is limited by underdeveloped infrastructure and lack of policy framework guiding its use. Clearly lacking was programs on legal and ethical frameworks of eHealth. WHO, however, cites among limitations of the research methodology is that 'it was not possible to determine whether they had the collective eHealth knowledge to answer each question.' Nevertheless, this is a starting point to glean the current state of eHealth capacity in the country.

\section{eHealth Research and Innovation}

Research and innovation in eHealth, as with other fields of inquiry, require cogent thought in planning and execution. eHealth applications and research developed in the country are listed in Table 1. The list is not exhaustive, however; on closer perusal, all are Manilabased researchers, although most field applications were in rural communities of the Philippines. The list offers a glimpse of the emerging players in the eHealth field in the Philippines.

\section{Framing the Country's eHealth Research Targets: The National Unified Health Research Agenda}

The National Unified Health Research Agenda (NUHRA), spearheaded by the Philippine Council for Health Research and Development - Department of Science and Technology (2011), serves as the country's template for health research and development efforts. This serves as the research guide of the National Telehealth Center's telemedicine research-service program that began in 2004. Dubbed Instituting the National Telehealth Service Program (NTSP), it is among NUHRA's output, and implemented in 2007-2010. It had two components: Emergency Care and Coordination Services, (or Project ECCS) and Project Lifelink. ECCS created a telecenter for experts, and enabled the development of Automated Triage, a tool for facilitating the transfer of referrals between doctors in different locations; Expert Interface, an electronic medical record for toxicologists; and ESP, a clinical decision-support system. Project Lifelink, on the otherhand, involved the development of a custom-designed scientific instrument named RxBox, a machine capable of measuring vital signs (heart rate, ECG, blood pressure, pulse rate and oxygenation) and transmit this data through both the Internet and GSM network to a medical specialist in a different location. Among others, this was a collaborative effort with various units of the College of Engineering, University of the Philippines Diliman.

For 2011 to 2016, the NUHRA again identified information and communication technology for health as among its priority research areas. This requires 'development of user-friendly ICT solutions to accelerate the gathering and processing of health and related information for policymaking, and to deliver quality healthcare services. It includes innovations in Public Health Surveillance/ Health Intelligence Systems, Telehealth services and systems, Interface for ICTenabled medical devices, and ICT-enabled health services.'

\section{eHealth Research Initiatives of the Department Of Health}

There are a broad range of surveillance systems reflective of the control of tropical to non-communicable diseases including injuries, monitoring prices of pharmaceutical products to adverse drug reactions, as well as databases of health personnel and facilities. Generally, aggregated health information is available to the public from the portals of each of these, accessible via the website of the DOH's UHMIS Unified Health Management Information System. Typically, these systems are made in collaboration with consultants from the academe and/ or the private sector; many are supported by international development organizations in health. Each of these health information systems has its own training program for end-users and administrators. Some of the Information Systems that the Department of Health has are as follows: (1) National Health Data Dictionary, (2) National Electronic Injury Surveillance System, (3) Kontra-Paputok Reporting System, (4) Electronic Essential Drug Price Monitoring System, (5) Integrated Drug Test 


\begin{tabular}{|c|c|c|c|}
\hline Date & Title / Topic of Research & $\begin{array}{l}\text { Proponent/ Organization (Philippines; } \\
\text { international collaborators are no longer cited) }\end{array}$ & Funding Organization \\
\hline 2003 & $\begin{array}{l}\text { A Community-based Child Injury Surveillance System Rapid Data Collection Using SMS: } \\
\text { Community Health Information and Tracking System }\end{array}$ & $\begin{array}{l}\text { Herman Tolentino, Alvin Marcelo, University of Philippines } \\
\text { Medical Informatics Unit }\end{array}$ & PAN Asia ICT R\&D \\
\hline 2004 & Water, Sanitation and Hygiene/ eWASH & Molave Development Foundation & PAN Asia ICT R\&D \\
\hline 2005 & $\begin{array}{l}\text { M-DOK-Mobile Telehealth and Information Resource System for Community Health } \\
\text { Workers }\end{array}$ & Ayedee Ace Domingo, SynapseHealth Solutions, Inc. & $\begin{array}{l}\text { IDRC-Canada through Information } \\
\text { Society Innovation Fund }\end{array}$ \\
\hline 2005 & $\begin{array}{l}\text { Implementation of wireless last mile telephony solution for information sharing and } \\
\text { disaster mitigation in the rural Philippine setting }\end{array}$ & $\begin{array}{l}\text { Denis Villorente, Department of Science and Technology } \\
\text { Advanced Science and Technology Institute }\end{array}$ & IDRC-Canada \\
\hline $\begin{array}{l}2008- \\
2010\end{array}$ & $\begin{array}{l}\text { Lifeline Online: E-Counseling and the Wellbeing of Overseas Filipino Workers and their } \\
\text { Families }\end{array}$ & $\begin{array}{l}\text { Ma. Regina Hechanova, Ateneo de Manila University, } \\
\text { Department of Psychology }\end{array}$ & IDRC-Canada through SIRCA \\
\hline $\begin{array}{l}2007- \\
2010\end{array}$ & $\begin{array}{l}\text { Economic Evaluation Framework of Computerization in Hospitals - Pakistan; Philippines; } \\
\text { Afghanistan }\end{array}$ & $\begin{array}{l}\text { Alvin Marcelo, University of the Philippines, National } \\
\text { Telehealth Center }\end{array}$ & IDRC-Canada through PANACeA \\
\hline $\begin{array}{l}2007- \\
2010\end{array}$ & $\begin{array}{l}\text { Improving maternal health care services by using I ITs for remote consultation and } \\
\text { education - Mongolia and Philippines }\end{array}$ & Irma Saligumba and Angelo Ramos, Molave Foundation & IDRC-Canada through PANACeA \\
\hline $\begin{array}{l}2007- \\
2010\end{array}$ & $\begin{array}{l}\text { Online TB Diagnostic Committees for Clinically Suspect Sputum Negative Patients in the } \\
\text { National TB-DOTS Program - Philippines; Pakistan }\end{array}$ & $\begin{array}{l}\text { Alvin Marcelo, University of the PhilippinesNational } \\
\text { Telehealth Center }\end{array}$ & IDRC-Canada through PANACeA \\
\hline $\begin{array}{l}2007- \\
2010\end{array}$ & $\begin{array}{l}\text { Framework for Primary health care providers to identify eHealth needs in a Primary Health } \\
\text { Care Setting - India; Pakistan; Philippines }\end{array}$ & $\begin{array}{l}\text { Emilyne De Vera and Edelina de la Paz, Health Action } \\
\text { and Information Network }\end{array}$ & IDRC-Canada through PANACeA \\
\hline $\begin{array}{l}2007- \\
2010\end{array}$ & $\begin{array}{l}\text { Basic Intervention Research on eHealth for the Visually Challenged“ Project- } \\
\text { Bangladesh; Philippines; India }\end{array}$ & $\begin{array}{l}\text { Emilyne De Vera, Marlene Bermejo and Edelina de la } \\
\text { Paz, Health Action and Information Network }\end{array}$ & IDRC-Canada through PANACeA \\
\hline $\begin{array}{l}2007- \\
2010\end{array}$ & $\begin{array}{l}\text { Community-based eHealth Promotion for Safe Motherhood: Linking Community Maternal } \\
\text { Health Needs with Health Services System - Philippines; Pakistan; Indonesia }\end{array}$ & Irma Saligumba and Angelo Ramos, Molave Foundation & IDRC-Canada through PANACeA \\
\hline 2009 & Health, emergency and disaster information using mobile and virtual earth technology & Ayedee Ace Domingo, SynapseHealth Solutions, Inc. & Information Society Innovation Fund \\
\hline 2010 & elMCI (Integrated Management Childhood IIness) & Michael Syson, Ateneo de Manila University & -- \\
\hline \multirow[t]{2}{*}{2010} & Amputee Screening via Cellphone NeTworking (ASCENT) & $\begin{array}{l}\text { Physicians for Peace, PGH/UERM, Smart Communications, } \\
\text { Ateneo de Manila Java Wireless Competency Center }\end{array}$ & - \\
\hline & SET (Sex-Ed Text) & $\begin{array}{l}\text { Peace Corps, Baguio Center for Young Adults, Save the } \\
\text { Children, Child and Family Services, Philippines Inc. }\end{array}$ & \\
\hline
\end{tabular}

Operations and Management Information System, (6) Adverse Drug Online Reporting System, (7) Health Record Number Registration System, (8) Health Facility Database System, (9) Hospital Reporting System, (10) Integrated DOH Licensing Information System, (11) Field Health Services Information System, (12) Health Clinic Information System, (13) Filariasis Information System, (14) Schistosomiasis Information System, (15) Integrated Chronic Non-Communicable Registry System, (16) Overseas Foreign Worker Clinic Uploading System, (17) Philippine Organ Donor and Recipient Registry System, (18) Philippine Persons with Disability Registry
System, (19) National Database on Health Human Resource, (20) Integrated TB Information System,, (21) Electronic Philippine Integrated Disease Surveillance and Response (ePIDSR), (22) Surveillance in Post-Extreme Emergency and Disaster (SPEED).

\section{eHealth Education in Institutions of Higher Learning}

In 1993, the College of Public Health University of the Philippines, Manila held a series of audioconferences with health professionals in the Southern
Philippines in coordination with the Memorial University of Newfoundland in Canada. The project developed the College's distance education and outreach programmes in the field of public health and increased access to continuing medical education opportunities for health professionals in the Philippines. The early experiences would form the base of the pioneering degree program offerings of the UP Open University, i.e. Master in Public Health offered in 1995, and Master in Hospital Administration in 1996. (Marcelo, 2006)

The UP Open University [UPOU] (n.d.) was established in 1995 as a de- 
liberate strategy to address 'the perennial challenge of providing quality higher education to a growing population distributed in over 7,000 islands, the UP, through the UPOU's open and distance learning, will allow wider access to quality education'. In its incipient years, distance learning was offered through 'guided independent study with monthly face-to-face tutorials at the UPOU Learning Centers and, in a few cases, teletutorials'. UPOU collaboratively conceptualized other health-re-

Box 1 Feature CHITS

CHITS (Community Health Information Tracking System) is an electronic medical record system for government-primary care health centers. It was developed by Dr. Herman I. Tolentino and Dr. Alvin B. Marcelo of the Medical Informatics Unit of the University of the Philippines Manila, in close collaboration with Dr. Marie Irene Sy of the Pasay City Health Office. It is built to help health workers store, process, and retrieve patient health records to aid patient care. It also an eSurveillance tool to help the health staff prepare reports for the Field Health Service Information System duly submitted to the provincial, regional and central offices of the Department of Health to monitor national health programs.

lated courses, in addition to the public health and hospital administration degree programs previously cited.

Around the mid 1990s, Caring for the Special Child, a non-formal course was developed and offered by the UPOU in cooperation with medical experts from the UP College of Medicine and the Philippine General Hospital; this included specially developed audio-visual materials. Other non-degree programs began to be offered: Information Technology in Health Research in 1999, Caring for the Older Person and Community Mental Health in 2007 and onwards.

The College of Engineering in the UP Diliman campus has incorporated eHealth related research for its students beginning 2008 up to the present, in col- laboration with the UP Manila National Telehealth Center. This span disciplines of computer science, industrial engineering and electrical and electronics engineering. Vice Chancellor for Research Dr. Luis Sison spearheaded the development of an RxBox, a telemedicine device used to transmit medical signals between health professionals in rural remote communities of the country and specialists in urban centers.

\section{The University of the Philippines Manila, the National Health Sciences Center and eHealth}

The University of the Philippines Manila, the national health sciences center, began formalizing its initiatives in ICT in health within its campus. Already cited are some of the pioneering efforts of the College of Public Health and medical experts in collaboration with the UPOU.

In 1997, the Medical Informatics Unit (MIU) of the UP College of Medicine was organized. In 1998, the National Telehealth Center (NTHC) of the UP Manila was established with a mandate to "improve health of Filipinos through the optimal use of ICT". It was envisioned to conduct continuing education, research, and information exchange among health professionals and the general public using emerging information communication technology (ICT). It was initially planned to establish satellite nodes or offices in various parts of the country through the Ministry of Health regional medical centers and hospitals, whose experts are duly recognized by the Philippine Medical Association affiliate societies and other health professional organizations.

UP Manila's initial investments in eHealth focused on building internal (University) capacities in ICT, i.e. in infrastructure and more importantly, among its faculty members. On their return to the Philippines after training abroad, they would continue as the core faculty of the UP College of Medicine MIU, and the NTHC, escalating work in eHealth in the University and in the country. From the incipient years of a purely service or administrative arm of the medical college that integrated ICT use to facilitate internal operations, the MIU grew to serve academic and research purposes. Specifically, in 2004 the MIU organized its Master of Science in Health Informatics (MSHI); this is first and only program of its kind in Southeast Asia region. This is a joint course offering of the College of Medicine, in charge of the Medical Informatics track, with the College of Arts and Sciences, which offers the Bioinformatics track. In the same year, it also launched the Moodle-based content management system OSIRIS, or Organ System Integrated Medical Curriculum and Research Information System, for use by faculty and students. The 'program offers a unique approach to learning health informatics by putting emphasis on communitybased and community-managed health information systems that are appropriate for resource constrained environments. It is also unique for its heavy adoption of the principles of primary health care in its curriculum design and implementation'.

In basic medical education, the national health information system and UP initiatives is introduced by the MIU in a four-hour session in the freshmen year, beginning 2004. In the same academic year, junior medical students used SIMDOTS in their Internal Medicine course; it is an eLearning tool simulating case management of TB cases developed by the MIU. SIMDOTS was an innovation of the Master TB Educator Award grant to the UP College of Medicine by the Philippine TB Initiatives by the Private Sector project of the USAID and government of the Philippines. An elective in medical informatics is offered for sophomore medical students; about 10-15 choose this course annually since it was offered in academic year 2005-2006.

Similarly beginning 2005, senior medical students rotating in Community 
Medicine began using MIU's Community Health Information and Tracking System (CHITS), developed through the support of the International Development Research Center of Canada. CHITS, as presented in Box 2, is a combined electronic medical record for patient care and an electronic surveillance tool for health programs in government primary care health centers in Pasay City. Among others, CHITS is an academic strategy of the UP to educate future physicians on health information management, and the use of electronic health records.

Aside from CHITS, UP medical students (and resident physicians) learn to use another electronic medical records system, the ISIS or Integrated Surgical Information System, for hospitalized patients of the Department of Surgery, UP-Philippine General Hospital. This was also built using free and open source tools by the Department of Surgery and the MIU. ISIS was embedded into the academic clinical rotations in Surgery for four and eight weeks during their senior and internship years, respectively. There are 160 and 200 medical trainees, respectively, who would use ISIS annually, and about 50 clinical residents in Surgery. The ISIS introduces research management information systems to medical students, surgical residents and faculty, alike.

The College of Arts and Sciences comanages and offers the MSHI Bioinformatics track. Its Computer Science program has recently collaborated with the MSHI Medical Informatics track, as well as the College of Dentistry. The latter spearheaded the development of an electronic dental record for use in its clinics in the College as well as in the Philippine General Hospital.

The UP Manila Information Technology Council, led by Dr. Serafin Hilvano, spearheaded collaborative work between the UP Manila and the Advanced Science and Technology Institute, as well as with various medical institutions in Asia, belonging to the Asia Pacific Network. Regularly held are eLearning / videoconferences involving real-time demonstration of sur-

Box 2 eHealth Education: Elements of Health Information Management discussed through CHITS

CHITS use opens up avenues for discussion of a variety of topics related to health information management. However, with the current set-up of limited teaching hours, these are delved into in an introductory, even superfical, manner only:

1. CHITS necessitates discussion on patient privacy, information confidentiality, ownership, security, and data quality.

2. It reinforces principles of bioethics discussed in other courses in UP education, but this time, tackled in the context of government health service and programs, and information management.

3. Likewise, CHITS, as a tool in health systems development, demonstrates the universal applicability of the principles of the WHO Alma Ata Declaration of Primary Health Care people-centrism, participation, inclusion, and community-building, open access availability, affordability and accessibility of resources to all, and resource sharing.

4. It reinforces the importance of evaluation of population health outcomes by showing students how patient data is automatically sorted and easily retrieved.

5. It underscores the advantages of digitized data and the campaign for computerization. Digitalization modifies analogue or paper-based data to a format useful to stakeholders other than the one who generated the data. This digitized data now has the capacity now to cross time and geographical boundaries, allowing reuse of data. This is especially important for decision-making at various policy levels of the health system. Both these characteristics make research less daunting.

6. CHITS, at best, only introduces the Philippine national health information system. It shows the data requirements of government priority programs to promote health (CHITS modules on EPI, maternal health) and manage infectious diseases (notifiable diseases, NTP/ national TB program). Outright, it presents health systems performance measurements. It provides data that elucidate specific demographic factors that act as significant determinants of the community's health status.

7. CHITS opens up an avenue for discussion on weaknesses of the present Philippine health information system (discussed above), and show ICT innovations of the UP and other health informatics practitioners towards addressing these.

Building capacities among future physicians (and in-service professionals) to be effective the health managers demands more than the current available academic time and the introductory nature of these discussions. The present state is not something to be happy about. One has to consider the critical nature of health information systems in improving community and national health outcomes; the role of the physician, and other health professionals, in this cannot be undervalued.

This is nevertheless a good starting point. One can only be optimistic that there will be more opportunities for expansion in the near future.

gical procedures between or among the Philippine General Hospital Department of Surgery with counterparts in various University hospitals in Japan, Taiwan, Malaysia, Indonesia, Australia, South Korea, Hong Kong and Vietnam.

\section{eHealth Education in Other Institutions in the Philippines}

The De La Salle University (DLSU) has incorporated health informatics to its six degree programs. Table 2 presents details the weight and its equivalent number of hours devoted to the subject. A typical full time student would complete 15-18 units per semester.

The University of Santo Tomas Faculty of Medicine and Surgery's Dr. Hubert G. H. Wong Medical Informatics Center provides a course on Medical Informatics to all incoming freshmen taking up Medicine and is "envisioned to facilitate research for biomedical knowledge and information."

St. Luke's College of Medicine Masters in Molecular Medicine offers a Bioinformatics and Medical Informatics 
course. The Ateneo de Manila University offers a three unit elective in health Informatics; the Ateneo School of Medicine and Public Health also incorporates discussions health information management in its double degree program Doctor of Medicine and Master of Management.

\section{Nursing Informatics}

The educators in nursing profession in the Philippines pride themselves for instituting a landmark national policy in eHealth education: in 2009 the Commission on Higher Education (CHED) issued CHED Memorandum No. 14 which called for the inclusion of health informatics in the nursing curriculum.

The Board of Nursing (n.d.) of the Professional Regulations Commission has been able to identify communication and records management as among the eleven National Core Competency Standards for Filipino Nurses, both are identified to be connected with nursing informatics. Thus, a graduate nurse is expected to show competence in communication through the use of appropriate information technology to facilitate communication as evidenced by the (1) utilization of a telephone, mobile

Table 2 eHealth, Health Informatics Education in the De La Salle University

\begin{tabular}{|l|l|l|l|}
\hline Course & Subject & Weight & Hours \\
\hline BS Computer Science & Health Informatics Short Course & & 24 hours \\
BS Nursing & Nursing 128: Nursing Informatics & $\begin{array}{l}2 \text { units Lecture } \\
1 \text { unit Laboratory }\end{array}$ & \\
& Health Informatics 1 & 2 units & 36 hours \\
BS Physical Therapy & HII-Information Technology & 3 units & 54 hours \\
& (Health Informatics) & & \\
& Health Informatics 1 & 2 units & 36 hours \\
& Health Informatics 2 & 2 units & 36 hours \\
BS Radiation Technology & Health Informatics 1 & 1 unit & 18 hours \\
Medicine & Medical Informatics 1-4 & & 28 hours \\
Graduate in Midwifery & HII-Information Technology & 3 units & 54 hours \\
& (Health Informatics) & & \\
\hline
\end{tabular}

phone, and electronic media; and (2) utilization of informatics to support the delivery of healthcare. Likewise, graduate nurses are believed to show competence in records management by utilizing a records system such as Kardex or Hospital Information System [HIS].

For post-graduate nursing studies, St. Paul University Philippines (2011) offers a nursing informatics course for their Doctor of Nursing Science students which "deals with the use of information and communication technologies for health (ICT4Health) in capabilities of a nurse as an educator, researcher and clinician." On the other hand, Trinity University of Asia (2010) offers their health informatics course among students as a 3-unit cognate, which the students can opt to choose upon completion of their required academic units in the program.

\section{Informal Training Courses}

A broad range of seminars and trainings to educate students, health and IT professionals on opportunities on health informatics are being conducted by the center to increase capacities on eHealth. Resource persons are pioneers in health informatics in the Philippines who practice the field in their institutions.
Among the end goals of each seminar and training is to open up a new perspective on advancing health care in the country through eHealth. Seminars and trainings of the NTHC are accredited by the Professional Regulations Commission for Continuing Professional Education (CPE) units.

\section{Available Short Courses at UP Manila National Telehealth Center}

\section{1 eHealth Seminar}

The NTHC eHealth Seminar began in April 2010 as the Seminar on Health Informatics. It has since been offered 14 times and participated in by 2094 students and professionals. It introduces the rationale and basics of eHealth, the need for standards, ethics and privacy of patient records. It showcases the program areas of NTHC (eRecords, eLearning, and eMedicine). It is an eight-hour conference that uses lecturettes, case discussions, audiovisual presentations, and table top exercises as teaching methods.

\section{2 eHealth Training for Educators of the Health Professions}

eHealth Training for Educators of the Health Professions (or the eHT) is an intensive three-day hands-on training designed for faculty members of health professions schools. The course enables educators to appreciate the value of eHealth in moulding highly competent, evidence-based, relevant and more importantly, ethical health practitioners, researchers and educators. The course also demonstrates how educators can seamlessly integrate learning management systems and electronic medical records in their instruction.

\section{Certificate Course on eHealth and Telemedicine}

The lack of medical specialists in the rural areas have prompted this training program to build capacities among, doctors in remote rural communities to 
manage patients with difficult medical conditions. The training program is recently updated and is offered as a sixmonth blended learning course that combines face-to-face learning, field practice and tele-mentoring. This is intended for referring physicians - the DOH Doctors to the Barrios and Municipal Health Officers who enrol in the National Telehealth Service Program jointly offered by the DOH and the NTHC.

The face-to-face seminar workshop uses lecturettes and break-out sessions for hands-on skills building on telemedicine tools for clinical referral to domain experts / clinical specialists based in the Philippine General Hospital. The course also provides doctors with clinical updates relevant their practice in the field. Since 2007, NTHC has been providing assistance to 295 doctors in rural areas through telemedicine services.

\section{CHITS Training: Certificate Course on eHealth and eRecords}

CHITS (Community Health Information Tracking System) is an electronic medical record system for governmentprimary care health centers. It was built to help health workers store, process, and retrieve patient health records to aid patient care. It was also designed as an eSurveillance tool to help the health staff prepare reports for the Field Health Service Information System duly submitted to the provincial, regional and central offices of the Department of Health to monitor national health programs.

Empowerment at the health center underpins CHITS Training. Doctors, nurses, midwives (and other allied health staff) are equipped with computers skills, embedding these in their work flow. Computer literacy training is vital to CHITS since most health workers are middle-aged, have not used a computer before or at best, are vaguely familiar with its use. Trainers create a fun-learning environment allowing health workers to play computer games to practice their skills in using the mouse and computer. By 2012,
CHITS would have been installed in 135 health centers nationwide, and engaged up to about 1370 primary care health workers

\section{elHealth Trainings Offered by Other Institutions}

The Asian Institute of Management (2011), a graduate school of business and business management research offers a health informatics short course. The Medical City, a tertiary hospital in Manila offers a fourteen-week nursing informatics training program as well as telemedicine training for use by its clinical staff in its network of clinics across the country (Muin, 2012). My Health Clinic, a group of seven clinics based in shopping malls in Metro Manila and Cebu has a similar set up; they describe up to 200 specialists available, on call through telemedicine, to the primary care physicians or nurses attending to the patients in their clinics. Currently available is a call-center service, NurseKol (Asian Telehealth Services, Inc.) where patients with health questions are provided answers by nurses, based on clearly defined medical / clinical protocols. Personnel in their clinic system are thus trained to use their telemedicine systems.

\section{Enabling eHealth in the Philippines}

The movement in eHealth in the Philippines was made possible by generous support and continued collaboration among various sectors. More importantly, these networks provided platforms for eHealth education and capacity building.

\section{PREGINET}

The Philippine Research, Education and Government Information Network
(PREGINET) is the only research network which interconnects researchers, academicians, and government institutions for sharing online information, resources, and reference for their academic and research extension work. Setup providers dedicated infrastructures for high-bandwidth internet exchange for video-conferencing. With PREGINET, internet traffic and online outages of the mainstream internet provided to the general public is dissipated. PREGINET made possible the regular eLearning/ videoconferences of the Philippine General Hospital Department of Surgery with counterparts in various University hospitals in the Asia Pacific, i.e. Japan, Taiwan, Malaysia, Indonesia, Australia, South Korea, Hong Kong and Vietnam which involved demonstration of surgical procedures.

\section{The Philippine Health Information Network}

The Philippine Health Information Network (PHIN) was launched in 2005 by its founding members-led by the DOH, National Statistics Office, National Statistics Coordinating Board, and Philippine Council for Health Research and Development. It aims to create and to sustain a collaborative effort among different organizations such as government agencies, donor organizations, academe, private sector, and others involved in health information. In 2007, aside from expanding its membership, PHIN completed its assessment of the country's health information situation and saw the need to develop a comprehensive and coordinated health and nutrition information system (HIS), thus aligning and harmonizing the efforts of all concerned agencies within and outside the DOH and efficiently producing reliable health information. It recognized while there was a workforce focused on health information management, these were not adequate; use of ICT, especially in the frontlines of patient care, was minimal. In 2011, as a participant of the Asia 
Pacific Forum on Health Information Systems, PHIN with other sectoral representatives assessed that the Philippines, while much have been achieved in the interim, challenges remain.

\section{eHealth as Part of the Philippine National Health Agenda}

In 2010, the Department of Health prepared the National eHealth Strategic Framework, 2010-2016. Its Vision: ICT supporting Universal Health Care to improve healthcare access, quality, efficiency, and patient safety and satisfaction, to reduce cost and enable policy makers providers, individuals and communities to make the best possible health decisions. Its mission is to effectively use ICT to improve health care delivery, administration and management, and in communicating health. The first of five goals speak of establishing enabling structures and policy; among its strategies is capacity building to achieve e-maturity among the health workforce. It also speaks of the need to build the infrastructure. The fourth goal is to institutionalize knowledge management systems to promote knowledge exchange and utilization especially at sub-national levels.

\section{ICT4H Consultative Group}

In late 2010, members of the academe, private sector and the government were convened by the Secretary of Health Dr. Enrique T. Ona. As a form of public private partnership, eight leaders were constituted as the ICT for Health (ICT4H) Consultative Group; the group expanded, although membership was mainly among Manila-based enthusiasts. The group's objective was to provide technical assistance to the Department of Health's Information Management System (IMS) in advancing eHealth in the Philippines. Four areas were identified as crucial to work on: the health sector's enterprise architec- ture, standards and interoperability, capacity building, standards compliance and a range of cross-cutting issues. After almost a year of monthly meetings, the ICT4H presented recommendations to the Health Secretary on building ICT capacities among the health workforce: Adopt a capability building roadmap with a vision of: All public health workers will be ICT literate by 2016

Further recommended are the following activities:

1. Conduct a Baseline Review and Training Needs Analysis

2. Develop a National ICT Competency Standards for Health Workers

3. Develop Health Training Program

4. Accredit Training Service Providers

5. Oversee Conduct of Training and Certification for ICT Courses

6. Lobby for Health Informatics in the Health Professions Curriculum

7. Press for ICT for Continuing Professional Education

\section{Health Informatics Organizations}

The Philippine Medical Informatics Society (n.d.) is an acknowledged proponent of open source development for health. Realizing that public health is for the public good, it maintains that all health applications must be open to peer review and analysis. Among the activities it has offered through its eight years were lectures from international medical informatics experts, seminars on use of online bibliographic databases, handheld devices, electronic health records, and security of electronic health information. The PMIS is a strong partner in the Standards for Health Information in the Philippines project as well as the BuddyWorks Telehealth Project and the upcoming Philippine National Health Information Infrastructure. The Society's bias is for the deployment of health information systems in support of national development and poverty alleviation through the full implementation of the Primary Healthcare Approach. Among the beneficiaries of its technical semi- nars are community health workers, government midwives, and private practitioners.

The Informatics Nurses Society of the Philippines (iNurse SP) Inc (n.d.) has been established as the lead nursing informatics organization in the country. As recognized by and partnered with PMIS, it serves as the Philippine representative to the International Medical Informatics Association vis-à-vis its IMIA - Nursing Informatics Special Interest Group. Currently, it works with agencies like Philippine Health Insurance Corporation, St. Luke's Medical Center, and is a member of the Asia eHealth Information Network (AeHIN), a group composed of Cambodia, Indonesia, Malaysia, Philippines, Thailand and Vietnam which came together to strengthen country-wide health information systems and strategic plans. It is spearheaded by five nurse advocates in guiding the practice of information and communication technology use in the health care setting.

\section{The Philippine eHealth Arena: Next Steps \\ Wanted: a Cross-pollination of Expertise}

eHealth education and training should be regarded from its development goal of addressing poor health and inequities in health. Thus, eHealth education should be viewed from a multi-disciplinary and multi-sectoral perspective, a cross pollination of expertise.

eHealth can facilitate flows of information, communications and coordination within and across the system and national borders. The term eHealth includes other categories such as mobile health (mHealth), telehealth and health informatics. It can automate and make services and processes more efficient. It has a role in informing decision-making with timely, accurate, 
and reliable data as well as data visualization. Well-designed health enterprise architecture that encourages interoperability within and across different systems is critical for strong health systems. It requires critical analysis of system workflows and the opportunity to reflect on system-wide effects whether they are aligned with strategic goals, including equity goals. (IDRC, 2011)

The NTHC of the UP Manila has engaged faculty from other disciplines in developing and evaluating its eHealth applications - public health policy and management, development economics, sociology and behavioral sciences, industrial engineering, computer science and electrical and electronics engineering and development communications.

\section{Multi-sectoral and ICT-enabled Action Needed to Achieve Universal Health Care}

The last fifteen months bore witness to many efforts at information sharing and integration between and among sectors, including that of the Monitoring of Vital Events through Information Technology and forums of the Interagency Committee on Health Statistics, the ICT4H Consultative Group, Connectathons organized by the NTHC in cooperation with the DOH with support from the World Health Organization, as well as Interoperability Forums organized by the NTHC through the support of the UNICEF and NEDA involving the $\mathrm{DOH}$, Departments of Interior and
Local Government, Education, Social Welfare and Development.

In 2010, the call for universal health care was made by the new President of the Philippines, recognizing that the Millenium Development Goals can be reached by 2015 only if fundamental reforms in the health sector, including that of multi-sectoral approaches be adopted. Efforts in the last few months are encouraging, and need to be regarded as systematic steps in enabling the health sector with ICT and information management skills as among the critical means to better health.

In 2012, on its reorganization, the PHIN organized several technical working groups, including that on capacity building for the Philippine HIS, and likely adopt many of the recommendations of the ICT4H Consultative Group.

eHealth in the Philippines is emerging, benefitting from clear policies emanating from government and from partnerships with local and international organizations.

\section{References}

AIM Center for Development Management. Health informatics; 2011. Retrieved from http:// www.cdm.aim.edu/index.php/international-healthmanagement/22-health-informatics

Board of Nursing - Professional Regulation Commission. (n.d.). National Competency Standards for Filipino Nurses. Retrieved from http://bon2. cebuinternetsolutions.com/index.php/downloadsbon-sub-menu-41/13-nursing-manuals-anddocuments/261-national-competency-standards-forfilipino-nurses.html

Commission on Higher Education. Policies and standards for bachelor of science in nursing program; 2009. Retrieved from http://www.bonphilippines. org/images/downloads/CMO14series2009BSN.pdf Informatics Nurses Soc. of the Philippines Inc. (n.d.). Home. Available from www.inursesp.org
International Development Research Center. Narrative Report on the SEARCH RTD. Canada; July 2011.

International Telecommunication Union. Philippines case study; 2011. Retrieved from http://www.itu. int/ITU-D/ict/cs/philippines/index.html

Jayasuriya, R. Health informatics from theory to practice: lessons from a case study in a developing country. Medinfo 1995;8 Pt 2:1603-7.

Marcelo A. Health Informatics in the Philippines; 2006. Retrieved fromhttp://ibir.tmu.edu.tw/bitstream/ 987654321/23539/1/Health\%20Informatics $\% 20$ in \% 20the \%20Philippines.pdf

Muin, M. Nursing informatics training program; 2012. Retreived from http://mikemuin.com/work/nursinginformatics-training-program-at-the-medical-city/

National Epidemiology Center. (n.d.). Field Epidemiology Training Program. Retrieved from http://nec.doh.gov.ph/index.php?option= com_content\&view=article\&id=12\&Itemid=26).

Philippine Council for Health Research and Development National unified health research agenda: 2011-2016; 2011. Retrived from http:/www.pchrd.dost.gov.ph/ index.php/downloads/publications/nuhra/national? download $=150 \% 3$ Anuhra-2011-2016

Philippine Medical Informatics Society. (n.d.). About the society. Available from http://www.philmedinfo. org/about-the-society/

St. Paul University Philippines. Computers in nursing - Baguio; 2011. Retrieved from http://lms.spup. edu.ph/course/info.php?id=198

Trinity University of Asia. Doctor in nursing management [Brochure]; 2010. Retrieved from http: /www.tua.edu.ph/tua_downloads/dnm.pdf

University of the Philippines Open University. (n.d.). History. Retrieved from http://www2.upou.edu. $\mathrm{ph} /$ about-us/history

World Health Organization. eHealth; 2012. Retrieved from http://www.who.int/topics/ehealth/en/

World Health Organization. Atlas eHealth country profiles: based on the findings of the second global survey on eHealth; Geneva: 2011. p. 182-3.

Correspondence to:

Portia F. Marcelo, MD

University of the Philippines Manila

National Telehealth Center

3rd Flr., IT Complex

Philippine General Hospital Compound

Manila, The Philippines

E-mail: portiamarcelo@telehealth.ph 